\title{
SOME CONSIDERATIONS ON THE FAULTING MECHANISM OF THE SOUTHEASTERN AKITA EARTHQUAKE OF OCTOBER 16, 1970
}

\author{
Takeshi Mrkumo \\ Disaster Prevention Research Institute, Kyoto University, \\ $U_{j i}$, Kyoto, Japan
}

(Received January 16, 1974)

The faulting process of the southeastern Akita earthquake of October $16,1970(M=6.2)$ that took place on inland of the Tohoku region has been investigated from available seismic and geodetic data.

A synthetic study on the radiation pattern of $P$-wave first motions, spatial distribution of aftershocks, dynamic ground motions in the nearfield, vertical tectonic movements along a nearby leveling route, and on teleseismic observations of $S$ waves, suggests two possible faulting mechanisms. One is a thrust faulting of a western block over an eastern block along a westerly dipping fault plane with N-S strike. This mechanism seems consistent with tectonic features of this region, a belt-like distribution of earthquake damages along this trend, and with the location of the epicenter near the presumed extension of a fault caused by the 1896 earthquake. Another possible mechanism is also thrust faulting of a northeastern block over a southwestern block along a northeasterly dipping fault plane. Spatial distribution of aftershocks inclining northeastwards appears to support the second mechanism.

Comparisons of the various observations with the corresponding theoretical calculations for a number of fault models slightly favor the first mechanism, but cannot yield a definite conclusion. The fault parameters such as dimensions, seismic moment, average dislocation, rise time, fracture velocity and stress drop are estimated for four probable models. Pre-earthquake data are also examined in relation to the faulting mechanism.

\section{Introduction}

The southeastern Akita earthquake of October 16, 1970, with a magnitude of 6.2, took place on inland of the Tohoku region. The epicenter was located at $140^{\circ} 45^{\prime} \mathrm{E}$ and $39^{\circ} 12^{\prime} \mathrm{N}$, near the southern end of the presumed extension of the Kawafune fault caused by the Riku-u earthquake of 1896, which was the largest earthquake $(M=7.5)$ in this region. Tectonic structures of a green-tuff area in the region are characterized mainly by the N-S trend, and 
may be divided into the Japan Sea coastal area, the Dewa hills, inland basin area, Ôu high mountains and the Kitakami valley, which are bounded by geological faults or tectonic lines. The great Riku-u earthquake occurred in the inland basin, the west rim of which is bounded by a reverse geological fault with a western block uplifted. The Kawafune fault appeared almost exactly along its trend, and tectonic deformations associated with this fault movement also indicated a ground uplift of the western block and subsidence of the east side (Geological Survey Inst., 1971).

On the other hand, the 1970 earthquake did not yield appreciable surface faults except a number of small-scale ground fissures trending in the N-S direction, but earthquake damages were distributed in a belt-like zone extending for about $20 \mathrm{~km}$ just east of the presumed trace of the Kawafune fault (Geological Survey INST., 1971). From these evidences, it is suspected that the present earthquake might be closely related to possible movements of the southern part of the fault.

In this paper, we attempt to clarify the faulting process and tectonic implications of this earthquake by synthesizing available seismic and geodetic data including spatial distribution of aftershocks, the radiation pattern of $P$ wave first motions, strong ground motions in the near-field and vertical tectonic movements from leveling surveys. The $S$ waveforms recorded at teleseismic distances are also examined to test the reliability of the information obtained from the near-field data. Concerning the present earthquake, the Mrcroearthquake Research Group of Tohoku University (1971), Hase-

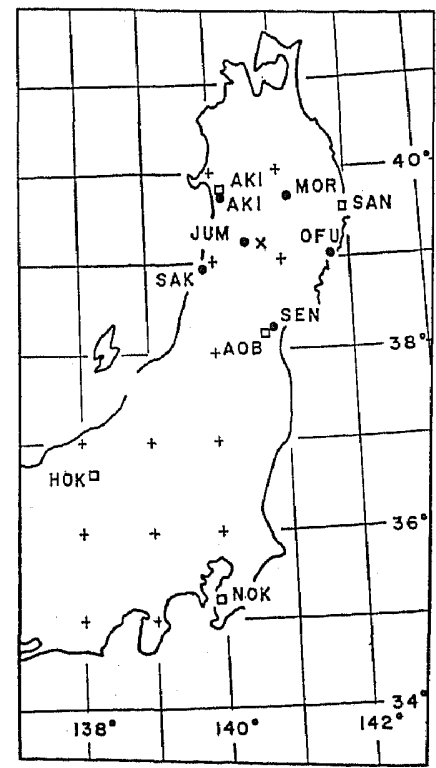

Fig. 1. Location of the epicenter (cross), JMA stations with strong-motion seismographs (solid circles), and crustal movement observatories where strain steps have been recorded (squares). 
GAWA et al. (1972, 1973a) and TAKAGI et al. (1973) have independently made similar investigations. An emphasis is laid in this paper to obtain unified fault models that could account for both dynamic and static observations, and to see whether the models are consistent with tectonics in the region.

Figure 1 shows the locations of the epicenter and recording stations. Solid circles indicate nearby JMA stations (except JUM) with strong-motion seismographs, and squares are crustal movement observatories belonging to several universities, where strain offsets have been recorded during this earthquake.

\section{Focal Mechanism}

The focal mechanism of the present earthquake is determined, with the double-couple assumption, from the radiation pattern of $P$-wave first motions recorded at Japanese and WWSSN stations. To estimate the emergent angle of each seismic ray from the focus to a station, an average crust-mantle structure in Northeast Japan is applied for the Japanese stations within epicentral distances of $600 \mathrm{~km}$, while the Jeffreys-Bullen velocity profile is used for the teleseismic stations. Figure 2 shows the radiation pattern projected onto the lower hemisphere of the Wulff net, where solid and open circles indicate the stations with compression and dilatation, respectively. Broken curves show possible ranges of two nodal planes, and two thick curves are drawn in most probable positions. We have two possible solutions for the choice of the fault plane; one is a nodal plane dipping almost westward striking north-south, and another is a northeasterly dipping plane. It is noticed that the strike and dip direction of the first nodal plane seems consistent with the tectonic features around the epicentral area described above. The decision of the fault plane, however, should be opened to further information from various observations.

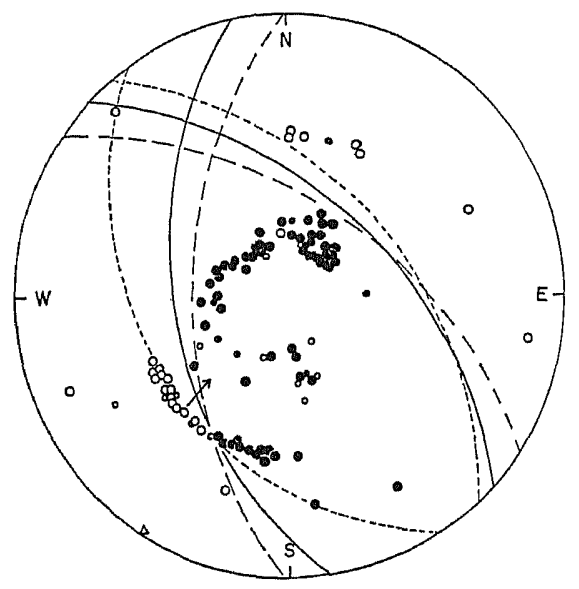

Fig. 2. Radiation pattern of $P$-wave first motions projected onto the lower hemisphere of the Wulff grid. Solid and open circles indicate compression and dilatation, respectively, and small circles are from somewhat less reliable reports and seismograms. Triangles correspond to nearby stations on the upper hemisphere, which are here projected through the center onto the lower hemisphere. Broken and dotted curves show possible ranges for two nodal planes, and solid curves are drawn in most probable positions. 


\section{Spatial Distribution of Aftershocks}

Aftershocks of the present earthquake have been observed over an extensive area by the Microearthouake Research Group of TOHOKU UNIVERsity (1971). Preliminary locations (1971) indicated that most of their epicenters were concentrated in an area with dimensions of about $14 \mathrm{~km}$ by $8 \mathrm{~km}$ extending approximately in the N-S direction, which seemed consistent with the strike of the first nodal plane, tectonic features and with earthquake damage distribution. More precise determinations (HASEGAWA et al., 1973a) show, however, somewhat modified distribution as reproduced in Fig. 3. The epicentral distribution of aftershocks that occurred within two days appears more elongated in the NW-SE direction, with the main shock situated near the southern end. Depth distribution projected in a profile along the $\mathrm{N} 48^{\circ} \mathrm{E}$

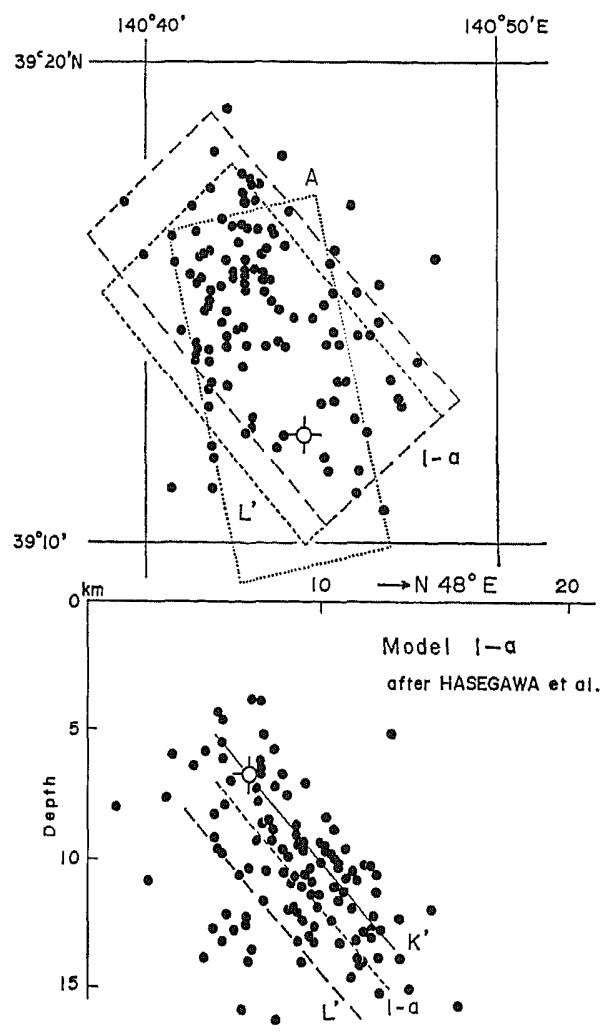

Fig. 3. Spatial distribution of the aftershocks that occurred on October 17 and 18, 1970 (after HASEGAwa et al., 1973a). The upper and lower figures show epicentral and depth distributions, respectively, together with the projection of probable fault models. Open circle indicates the position of the main shock. 
direction (HASEgawa et al., 1973a), as illustrated in the lower part of Fig. 3, indicates increasing focal depths towards northeast. If we assume that spatial distribution of aftershocks generally represents the location of the fault plane of the main shock, the above evidence seems to suggest that the second nodal plane dipping northeast presumably corresponds to the fault surface, but their rather scattered distribution does not provide a definite solution to this problem.

\section{Assumed Fault Models}

Taking the above situations into consideration, we assume a number of fault models with different orientations and dimensions, to see which of them can explain most reasonably various kinds of dynamic and static observations.

One standpoint is that: we consider that the earthquake was caused by thrust faulting of a western block eastward over an eastern block along a fault plane dipping westward. The plane has a dip direction of $261^{\circ}$ and a dip of $46^{\circ}$, and the slip direction of the upper block is defined by a plunge of $51^{\circ}$ and a rake of $43^{\circ}$. In this case, the fault dimensions are taken as $14 \mathrm{~km}$ by $8 \mathrm{~km}$ from the preliminary epicentral distribution. The hypocenter of the main shock lies at about $6 \mathrm{~km}$ from the south edge and assumed to have a depth of $3 \mathrm{~km}$. This model is hereafter denoted by Model $\mathrm{A}$. We also assume other Models B, C, D, . . etc. with fault displacements decreasing with depth,
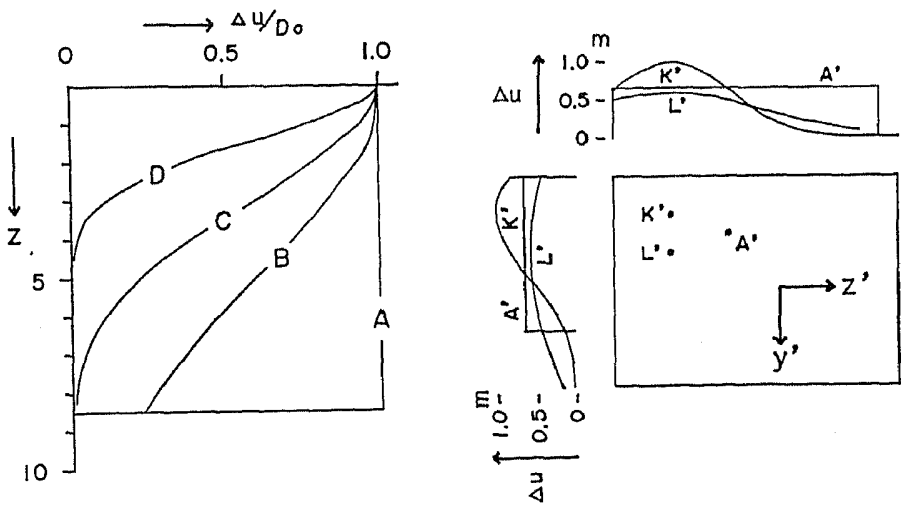

Fig. 4. Assumed fault displacements in various models. Left: fault displacements decreasing with depth for Models $\mathrm{A}, \mathrm{B}, \mathrm{C}$ and $\mathrm{D} . \Delta u, D_{0}$ and $z$ are the displacement across the fault plane, its maximum displacement on the ground surface and the depth in $\mathrm{km}$, respectively. Right: fault displacements decreasing towards both sides of the fault plane for Models $A^{\prime}, K^{\prime}$ and $L^{\prime}$. Solid circles inside the rectangle show the starting positions of fracture (hypocenter) on the plane for the three models, respectively. 
as variations of Model $A$, since it is likely that pre-earthquake stresses and frictional stress during faulting decrease with depth (CHINNERY and PETRAK, 1968; Mrkumo, 1973a). Assumed fault displacements are shown in the left side of Fig. 4.

Another standpoint is that faulting took place along the second nodal plane dipping northeast, as manifested by the inclined distribution of aftershocks towards northeast. The fault plane has a dip of $48^{\circ}$ towards $\mathrm{N} 48^{\circ} \mathrm{E}$, and the slip motion is defined by a plunge of $38^{\circ}$ towards $\mathrm{N} 115^{\circ} \mathrm{W}$. In model $\mathrm{A}^{\prime}$, we assume the same fault dimension and location of the main shock as in Model A. The revised epicentral distribution shown in Fig. 3 gives some difficulty to estimate uniquely the fault orientation and dimensions. One possible choice would be such one as enclosed by thick broken lines, which corresponds to Model 1-a of HASEgawa et al. (1973a), and we assume that the hypocenter of the main shock lies on the fault surface. This model is denoted by Model $\mathrm{B}^{\prime}$, which has dimensions of $15 \mathrm{~km}$ by $11 \mathrm{~km}$. Models $\mathrm{C}^{\prime}$, $\mathrm{D}^{\prime}, \ldots, \mathrm{K}^{\prime}$ and $\mathrm{L}^{\prime}$, with variable displacements on the fault plane, are also constructed as modifications of Model $\mathbf{B}^{\prime}$ to explain consistently both dynamic and static observations. As will be shown in later sections, displacements over the fault in these models are necessarily required to decrease northward to account for rather small vertical uplift there. Some of these models are given in the right side of Fig. 4, indicating displacements on the fault plane together with the assumed position of hypocenters. In Model L', we assume that the fault plane with dimensions of $13 \mathrm{~km}$ by $11 \mathrm{~km}$ lies near the lower boundary of aftershock distribution. It is also possible to take different orientations and dimensions as in Model 2-a and 3-a of HASEgawa et al. (1973a), in which the horizontal projection of the fault plane rotates more north-south and east-west, respectively.

\section{Dynamic Ground Displacements}

Strong ground motions have been clearly recorded during the present earthquake by the SMAC-B2-type accelerographs at Jumonji aparting only $23 \mathrm{~km}$ from the epicenter, and also at five JMA stations, Morioka, Akita, Sakata, Ofunato and Sendai with epicentral distances shorter than $80 \mathrm{~km}$ by the conventional JMA-type strong-motion seismographs. The locations of these stations are given by solid circles in Fig. 1. It is expected that these strong-motion records in the near-field provide useful information of the dynamic faulting process.

To estimate dynamic fault parameters from the observations, we calculate theoretical ground displacements and synthetic seismograms from various fault models, referring to the formulations given by MARUYAMA (1963) and 
HASkell (1969). Since the formulations are not complete for dynamic dislocations in a half-space, we apply simple corrections for the free-surface. This approach proved to give good approximations for direct body waves under specific conditions in view of complete theory of KAWASAKI et al. (1972) and SATo (1972). In the above computations, we assume that the initial rupture took place at the hypocenter and then fracture were propagated radially over the fault plane with a constant velocity. The rupture velocity is assumed to take values between 1.5 and $3.0 \mathrm{~km} / \mathrm{sec}$, while the compressional velocity is taken as $5.5 \mathrm{~km} / \mathrm{sec}$ which is somewhat smaller for the crustal velocity derived from explosion observations (Matuzawa, 1959; Hashizume et al., 1968 ), and the corresponding shear velocity is assumed as $3.2 \mathrm{~km} / \mathrm{sec}$. The time dependence of fault displacements is assumed to be a ramp function with rise times of $0.2-3.0 \mathrm{sec}$. The method of numerical calculations is the same as described in Mikumo (1973a).

Figure 5 shows the accelerograms recorded at Jumonji (STRONG Motion Earthouake Observation Committee, 1971). The natural period, damping constant, and the acceleration sensitivity of the instrument are $0.14 \mathrm{sec}, 0.6$ and $12.5 \mathrm{gals} / \mathrm{mm}$, respectively. Since the records involve much of high frequency components, it is preferable to transform them into the ground displacements in order to see their general behavior of the ground and to compare them more easily with theoretically computed traces. The method used here to get the ground displacements from the records was to Fourier-analyze the accelerograms, to correct the obtained amplitude and phase spectra for the instrumental response, and then to synthesize them back into the time domain. All the computations of the Fourier transform and synthesis were limited in the frequency range between 0.10 and $2.0 \mathrm{c} / \mathrm{s}$, rejecting both longrange fluctuation of zero-line and short-period noise. Two components of the

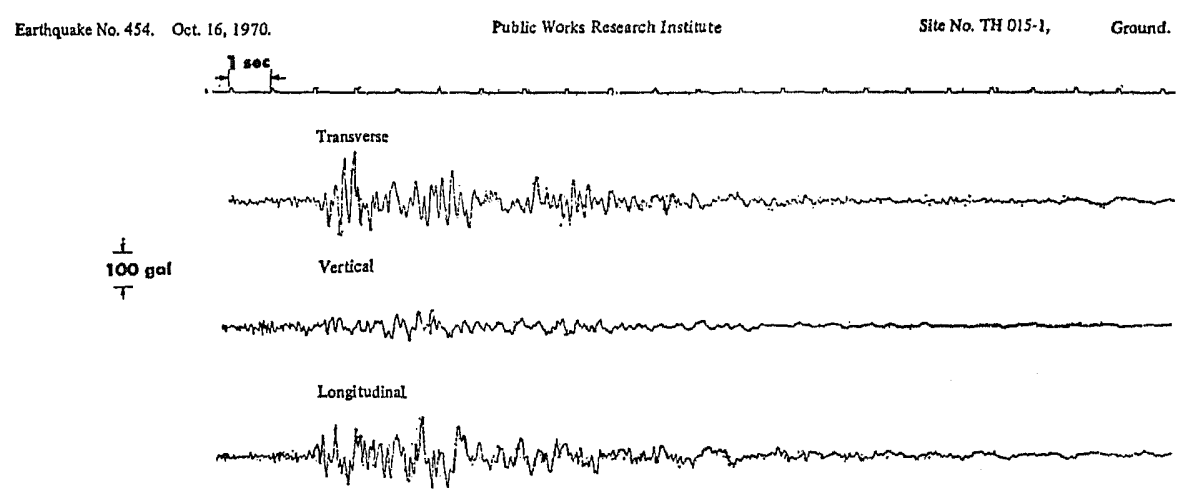

Fig. 5. Strong-motion records obtained at Jumonji $\left(\Delta=23 \mathrm{~km}, \varphi=\mathrm{N} 86^{\circ} \mathrm{W}\right)$, after Strong-Motion Earthouake Observation Committee (1971). 

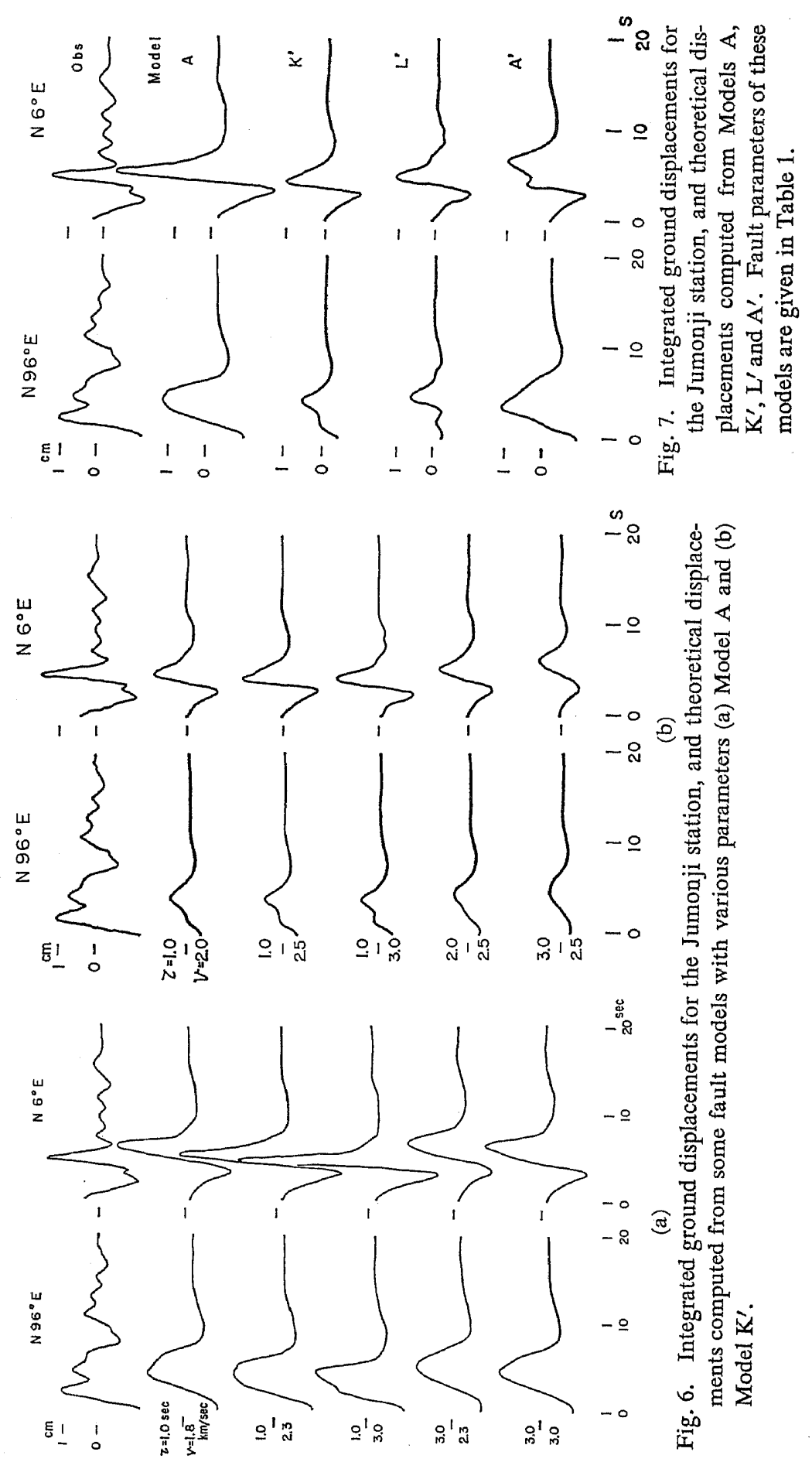
Table 1. Fault parameters.

\begin{tabular}{lrrrr}
\hline \multirow{2}{*}{ Parameters } & \multicolumn{5}{c}{ Models } \\
\cline { 2 - 5 } & A & $\mathrm{A}^{\prime}$ & $\mathrm{K}^{\prime}$ & $\mathrm{L}^{\prime}$ \\
\hline Dip (deg) & 46 & 51 & 48 & 48 \\
Dip direction (deg) & 261 & 43 & 48 & 48 \\
Strike (deg) & 351 & 133 & 138 & 138 \\
Slip direction (deg) & 43 & 261 & 245 & 245 \\
Fault length (km) & 14 & 14 & 15 & 13 \\
Fault width (km) & 8 & 8 & 11 & 11 \\
Dislocation maximum (cm) & 65 & 65 & 100 & 60 \\
$\quad$ average (cm) & 65 & 65 & 23 & 33 \\
Rise time (sec) & 1.0 & 1.0 & 1.0 & 1.4 \\
Fracture velocity $(\mathrm{km} / \mathrm{sec})$ & 2.3 & 2.3 & 2.5 & 2.7 \\
Seismic moment $\left(\times 10^{25}\right.$ dyne $\left.\cdot \mathrm{cm}\right)$ & 2.2 & 2.2 & 1.0 & 1.4 \\
Stress drop (bars) & 19 & 19 & 5 & 9 \\
\hline
\end{tabular}

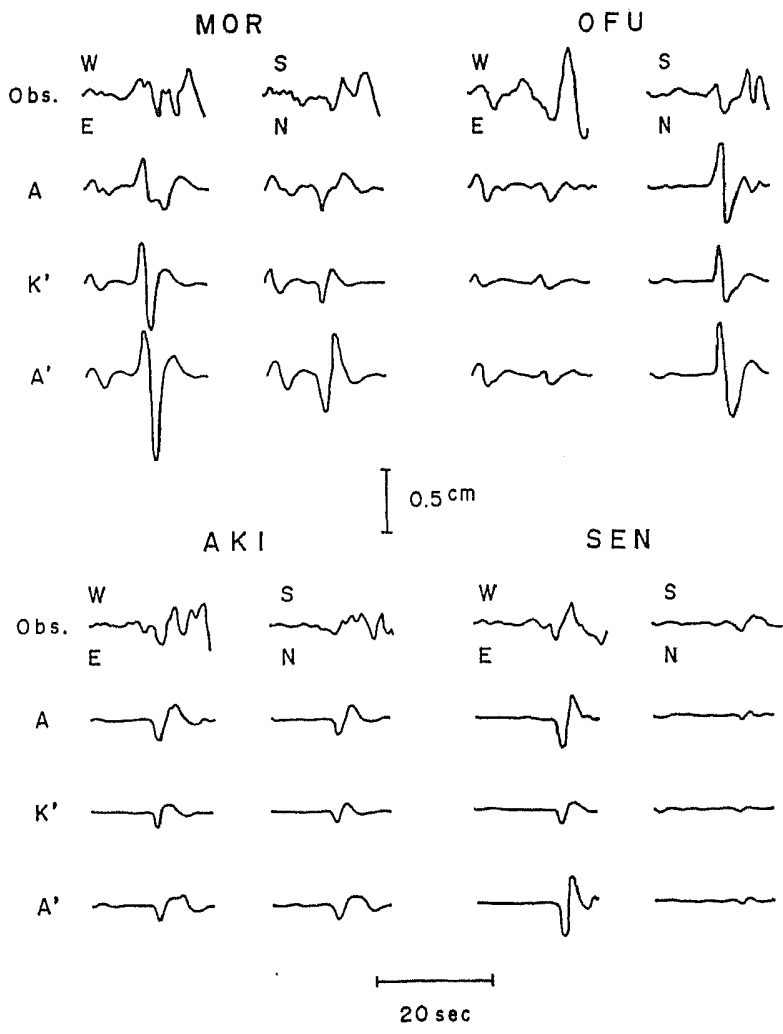

Fig. 8. Strong-motion records at four stations, Morioka, Akita, Ofunato and Sendai, and the corresponding synthetic seismograms based on Models A, $\mathrm{K}^{\prime}$ and $\mathrm{A}^{\prime}$. 
integrated ground displacements are shown in the uppermost traces of Figs. $6(\mathrm{a}),(\mathrm{b})$ and 7.

To compare with the ground displacements, we also apply a box-car type filter to theoretical displacements. The results for the Model A are given in Fig. 6(a) for five combinations of the rise time and rupture velocity. Deviations of the traces from the zero-line at the initial time are due to a phase shift in filtering process. Comparisons show that these computed traces give fairly good approximations to the integrated ground displacements, and the third traces with $\tau=1 \mathrm{sec}$ and $v=2.3 \mathrm{~km} / \mathrm{sec}$ appear to give a closest approximation to the both components.

Figure $6(\mathrm{~b})$ gives similar comparison between the ground displacements and five theoretical waveforms based on Model $\mathrm{K}^{\prime}$ which has a northeasterly dipping fault plane and variable fault displacements. The theoretical waveforms on $\mathrm{N} 6^{\circ} \mathrm{E}$ component seem generally consistent with the corresponding observation, but agreement is rather poor for those on $\mathrm{N} 96^{\circ} \mathrm{E}$ component. In Fig. 7 are again displayed theoretical traces from some other models with best combinations of the rise time and rupture velocity as indicated in Table 1. We notice that Model A seems to give a best explanation to the observed ground displacements, although the amplitudes are somewhat higher.

Figure 8 compares two components of the strong-motion records obtained at four JMA stations; Morioka, Akita, Ofunato and Sendai, with the
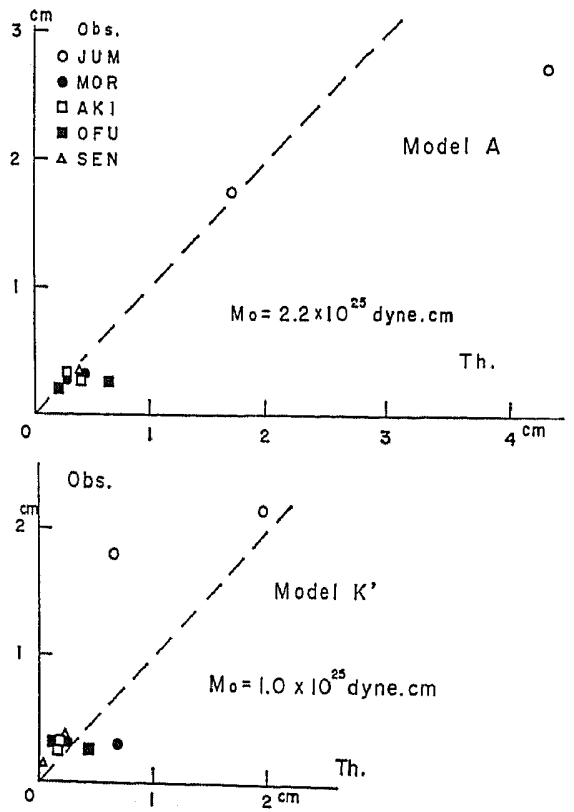

Fig. 9. Maximum double amplitudes on the recorded (Obs.) and synthetic (Th.) seismograms. Each station provides two amplitude data corresponding to two horizontal components. 
corresponding synthetic seismograms from three fault models. The synthetic seismograms are obtained by convolving theoretical displacements with the impulse response of the strong-motion seismographs used. The computed waveforms based on the three models do not show significant differences and agree fairly well with the first $15 \mathrm{sec}$ of the records. Later portions of the records are contaminated by surface waves, and cannot be explained by the present calculation. In Fig. 9 the maximum double amplitudes on the records are compared with those of the synthetic seismograms based on two probable models, including the integrated and computed ground displacements for the Jumonji station. This relation gives somewhat different estimate on seismic moment, $2.2 \times 10^{25}$ and $1.0 \times 10^{25}$ dyne $\cdot \mathrm{cm}$ for Models $\mathrm{A}$ and $\mathrm{K}^{\prime}$ respectively, if the rigidity is taken to be $3 \times 10^{11} \mathrm{dyne} / \mathrm{cm}^{2}$. By the similar way, the seismic moment is estimated as $2.2,3.5$ and $1.4 \times 10^{25}$ dyne. $\mathrm{cm}$ for other models $\mathrm{A}^{\prime}$, $\mathrm{B}^{\prime}$ and $\mathrm{L}^{\prime}$, respectively. Combining the estimated moment with the fault dimensions inferred from aftershock area, the average dislocation over the fault plane is estimated to be $65,65,70,23$ and $33 \mathrm{~cm}$ for Models $A, A^{\prime}, B^{\prime}, K^{\prime}$ and $L^{\prime}$, respectively. In the subsequent section, these estimates are tested whether they could be consistent with static observations.

\section{Static Displacements and Strain Changes}

One month after the present earthquake, the Geographical Survey INSTITUTE (1971) made leveling surveys along a route just north of the epicentral

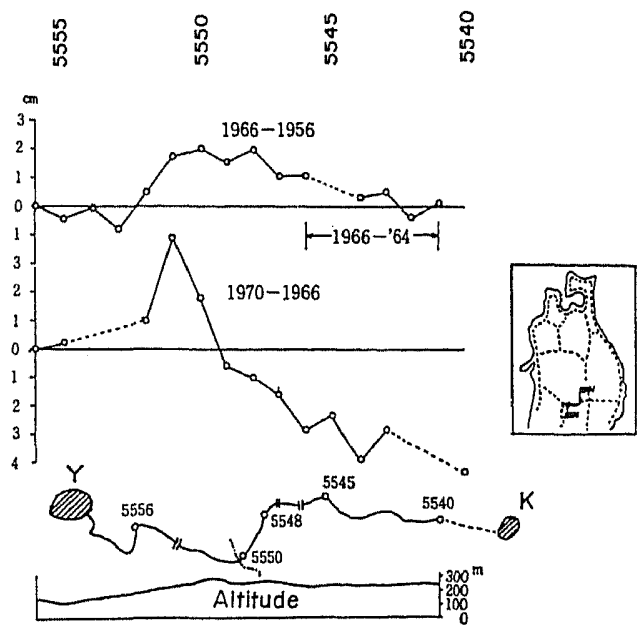

Fig. 10. Elevation changes along a nearby leveling route from Yokote $(\mathrm{Y})$ to Kitakami (K) during two periods 1956-1966 and 1966-1970. Lower figure shows the route and its altitude. Double cuts on the route indicate ground fissures in this area caused by the present earthquake. 

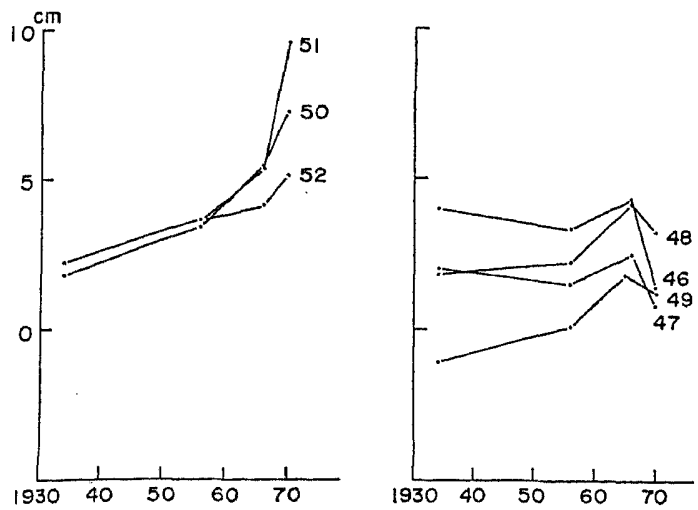

Fig. 11. Secular elevation changes of several sites on the leveling route during 1934-1970. (Recompiled from the GSI data assuming the level of B.M. 5558 in 1897 to be zero).

region from Yokote (B.M. 5556) to Kitakami (B.M. 5540), where similar measurements had been made in 1897, 1934, 1956 and 1966. The vertical tectonic movements derived from differences between these leveling data (Geographical Survey Inst., 1971) are reproduced in Fig. 10, which indicates a ground uplift of about $4 \mathrm{~cm}$ northwest of the aftershock area and a subsidence in the northeast side during 1966-1970. Most of these movements may be regarded as co-seismic displacements, although the subsidence over B.M. 5540-5445 might be considerably affected by the load from a water reservoir near the area (Geographical Survey Inst., 1971). During the period 1956-1966 prior to the earthquake, these areas indicate a slight uplift as shown in the same figure. Secular level changes from 1934 to 1970 , which have been recompiled from data of the Geographical Survey Institute, are also shown in Fig. 11.

We calculate here vertical displacements theoretically based on the various fault models assumed in the foregoing section, to explain the measured level changes during the earthquake. For these calculations, numerical integrations are performed over the assumed fault surface using MARUYAMA's formulations (1964) for static dislocations in a half-space.

Figure 12 shows the overall pattern of the theoretical displacements computed from Model A with a constant dislocation of $65 \mathrm{~cm}$. Model B, which has a maximum dislocation of $115 \mathrm{~cm}$ with a decreasing rate as indicated in Fig. 4, also yields a similar pattern as shown in Fig. 13. Thick and broken curves indicate contour lines of uplift and subsidence, respectively, and fine dotted lines show the leveling route. Since both the models correspond to thrust faulting of a western block eastward over an eastern block along a westerly dipping plane, the zone west of the fault is uplifted, and the east side 


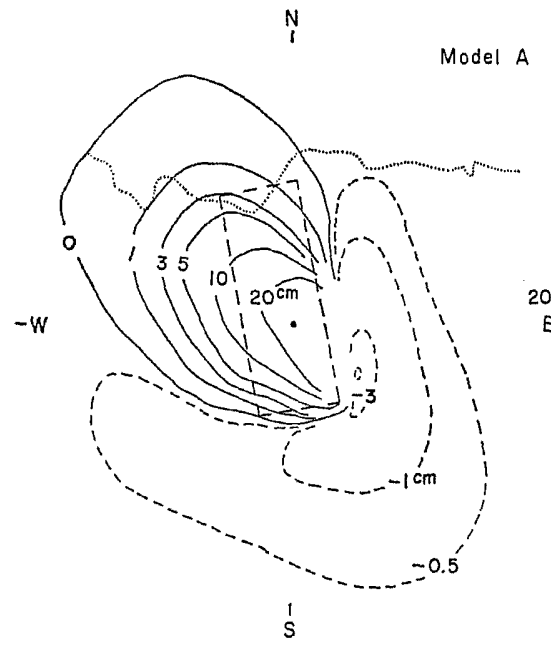

Fig. 12. Pattern of static, vertical displacements based on Model A. Solid and broken curves indicate uplift and subsidence respectively, and a fine dotted curve shows the leveling route. Rectangle and a small dot inside are the projection of the assumed fault plane and the position of the epicenter. The distances from the epicenter to the rims $N, E, S$ and $W$ are $20 \mathrm{~km}$. The same explanations apply to Figs. 13,14 and 15 .

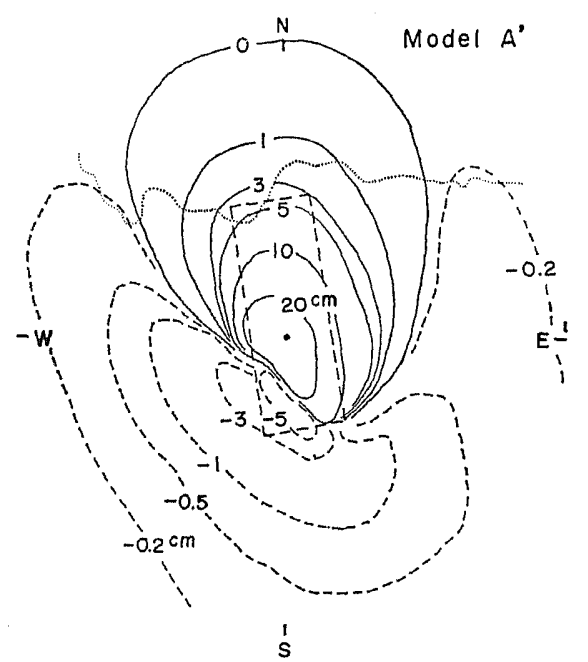

Fig. 14. Pattern of static, vertical displacements based on Model $\mathrm{A}^{\prime}$.

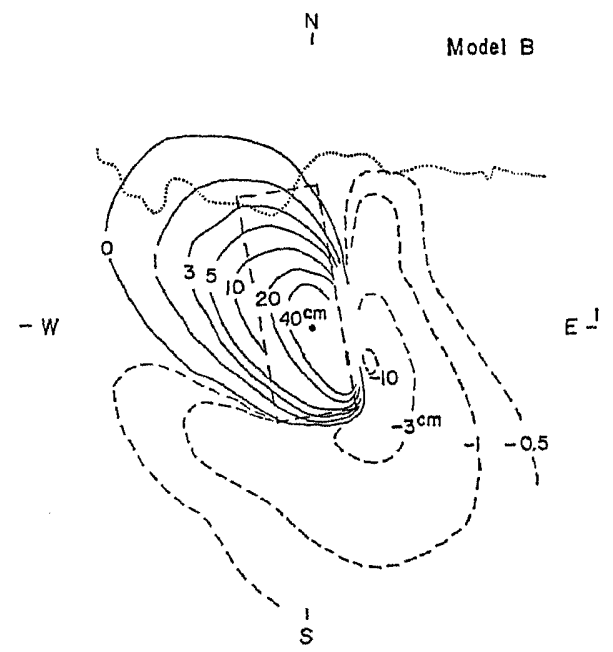

Fig. 13. Pattern of static, vertical displacements based on Model B.

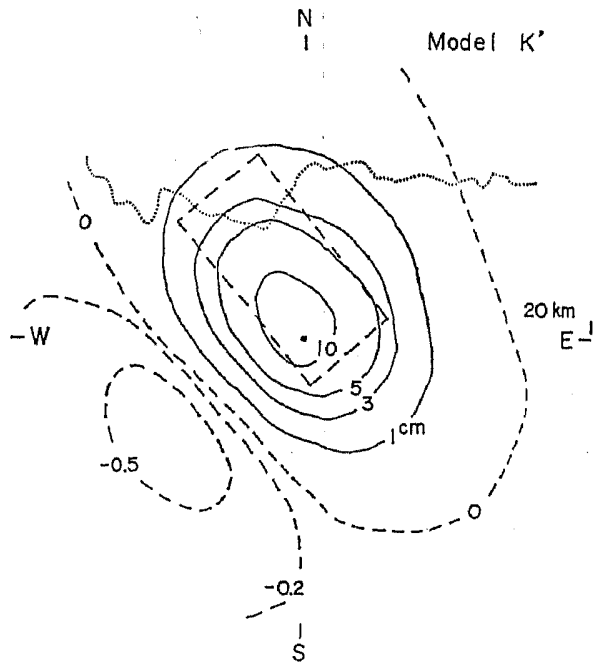

Fig. 15. Pattern of static, vertical displacements based on Model $\mathrm{K}^{\prime}$. 
subsided. This is consistent with tectonic features in this region. In Fig. 14, the displacement field for Model $\mathrm{A}^{\prime}$ is shown, which indicates major uplifts towards the north and subsidence towards the southwest direction. The similar pattern is shown in Fig. 15 for Model $\mathrm{K}^{\prime}$. This model, which has a configuration almost exactly based on aftershock distribution and decreasing dislocations towards both sides of the fault plane, gives uplifts centering in the epicental area.

In Fig. 16, the theoretical displacements from the above models along the leveling route are compared with the elevation changes derived from preand post-earthquake leveling surveys. It is immediately noticed that Model A with a constant dislocation of $65 \mathrm{~cm}$, which is consistent with the dynamic observations, yields a good agreement with the measurements in its peak displacement and also in its decreasing trend. Alternative models B and C, with decreasing dislocations with depth, can also explain the measured pattern almost equally well as Model $\mathrm{A}$, but these two models give dynamic amplitudes considerably larger than the recorded ground motions, and hence have to be rejected. The right-hand side in Fig. 16 corresponds to models with a northeasterly dipping fault plane. Theoretical displacements from Model $\mathrm{A}^{\prime}$ yield a similar trend in the west side of the fault zone but somewhat deviates from the measured movements in the east side. Model $\mathbf{B}^{\prime}$, with a constant dislocation of about $70 \mathrm{~cm}$ over an assumed fault plane consistent with the aftershock area, gives a peak static displacement as much as four times the
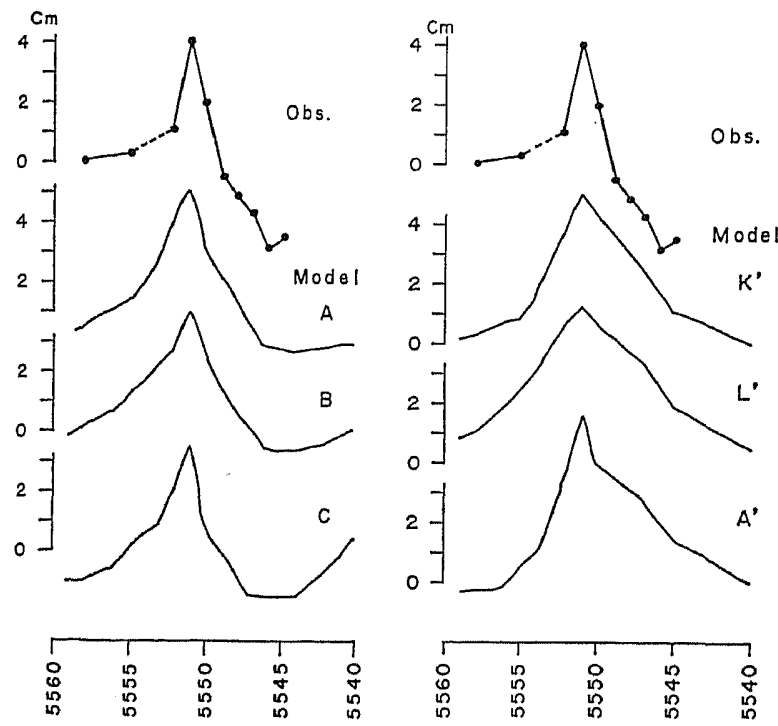

Fig. 16. Vertical, tectonic movements along the leveling route and the corresponding theoretical displacement computed from various fault models. 
measurements. We, therefore, have to consider different models such as $\mathrm{K}^{\prime}$ and $L^{\prime}$ with decreasing dislocations towards the north but with the same configuration. Although the computed peak displacements from Models $\mathrm{K}^{\prime}$ and $L^{\prime}$ almost agree with the measured values, we still notice some discrepancies in their decreasing trends. It should be noted here that the leveling route, unfortunately, does not traverse the central fault area, grazing only the northern rim. This situation makes it difficult to expect a definite conclusion from the above comparison.

At the time of the present earthquake, appreciable strain changes have been recorded on 12 strain meters at the 5 crustal movement observatories indicated by open squares in Fig. 1 and at another distant station (RESEARCH Group of Crustal Movements, 1971*; Ishil et al., 1971). To compare with these observations, we calculate theoretical strain changes that would be caused by the generation of faulting. Figure 17 shows a comparison between the recorded strain steps and the calculated changes from Models $A$ and $\mathrm{K}^{\prime}$. We see that these fault models give the right order of magnitude for 6 observations at 3 near stations in the Tohoku region, (the right-side points in the

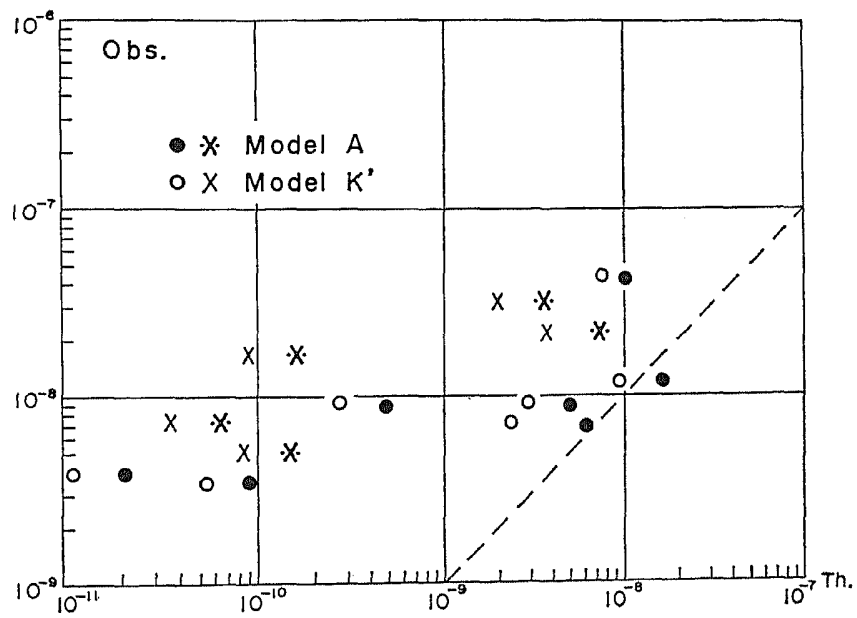

Fig. 17. Relations between the recorded (Obs.) and theoretical (Th.) strain changes at several stations. Solid circles and asterisks indicate the relation computed for Model $\mathrm{A}$, and open circles and crosses show the similar relation for Model $\mathrm{K}^{\prime}$. Asterisks and crosses imply that the recorded strain steps showed a reverse sense to theoretical prediction.*

* The recorded strain steps were compiled by the Research Group of CRUSTAL MOVeMENTS in 1971: at Akita, Sanriku and Aobayama are from observations made by Tohoku University, those at Hokushin and Nokogiri-yama are from observations of the Earthquake Research Institute, and one at Osakayama is from observations of Kyoto University. 
figure) but a reverse sense for two of them as marked by crosses and asterisks. Other 6 observations at relatively long distances (the left-side points in the figure) cannot be explained by these models, which may be due to local strain release or to instrumental effects. These situations are similar to the case of the San Fernando earthquake of 1971 (Mrkumo, 1973a) and the central Gifu earthquake of 1969 (Mrkumo, 1973b).

\section{Far-field Observations}

Seismic waves from the present earthquake have been recorded at a number of WWSSN stations at teleseismic distances, and the recorded $P$-wave first motions have been used to determine the focal mechanism, as described in Section 2. In this section, we attempt to obtain supplementary information for the focal process by using the waveforms and amplitudes of long-period $S$ waves. The method employed here is similar to that applied to intermediate and deep focus earthquakes (Mikumo, 1971), except including surface reflections.

We synthesize theoretical seismograms of $S$ waves on the basis of the fault models derived from the near-field observations, taking into account the effects of surface reflections near the source, attenuation and divergence during their propagation, crustal structure under recording stations and of instrumental response, and then compare them with the recorded waveforms. For shallow earthquakes as in the present case, the waves reflected at the ground surface near the focus arrive with considerable amplitudes shortly after direct waves. For the sake of simplicity, we assume here that synthetic waveform of the reflected waves may be expressed as a first approximation by a function identical to that of the direct waves but with different amplitude and a time lag. Then, we may write this relation;

$$
f_{r}(t)=-\frac{c_{r}}{c_{d}}\left(\frac{v_{d}}{v_{r}}\right)^{3} r_{c} \cdot f_{d}(t-\delta t)
$$

where $c_{r, d}$ are the spatial constants specified by the focal mechanism and the angle of emergent ray, $r_{o}$ is the refiection coefficient at the surface, $v$ is the wave velocity between the source and the surface, and suffixes $r$ and $d$ correspond to the reflected and direct waves, respectively. The time lag may be approximated by $\delta t=2 h / v \cos i$, where $h$ is the focal depth and $i$ is the angle of emergence. The reflected waves considered here are the $S V$ component of $p S$ and $s S$. We selected four stations, CHG, SHL, NDI and POO, where $S$ waves are clearly indentified on the vertical component with different amplitudes. Calculations of the above parameters for the stations show that contributions of $s S$ phase to direct $S$ waves range from 30 to $88 \%$, whereas those 
of $p S$ phase are less than 10\%. From the above estimates, we take only the $s S$ phase into account. The synthetic seismograms of direct $S$ waves, $f_{S}(t)$, are computed from some assumed models with dimensions, rise time, fracture velocity and average dislocation similar to those of Models $L^{\prime}$ and $A$, using the same method as used for deep-focus earthquakes (MIkumo, 1971). As the waveforms are not very different for the adopted models, the reflected waves $f_{s S}(t-\delta t)$ are superposed on $f_{S}(t)$ with a time lag $\delta t$ of about $7-8 \mathrm{sec}$. The composite theoretical seismograms are shown in Fig. 18 together with the recorded waveforms. It is seen that the synthetic seismograms give good agreement to the general features of the recorded waveforms. In the above computation, we neglected the effects of reflections at the boundaries of crustal layers around the source region, but the above agreement seems to justify the assumptions we made. Later phases such as SS and SSS do not appear in the present time interval.

Comparisons of the amplitudes on the recorded and synthesized seismograms at four stations yield the seismic moment of $2.1 \times 10^{25} \mathrm{dyne} \cdot \mathrm{cm}$. This is very close to the value for Model A estimated from the near-field observations, but almost twice of that for Models $\mathrm{K}^{\prime}$ and $\mathrm{L}^{\prime}$. The above estimate seems to suggest that the far-fied observations favor Model A.

The method used here can, in principle, be applied to $P$ waves, but the synthesized $P$ waveforms are sensitive to the determination of the time lag $\delta t$,

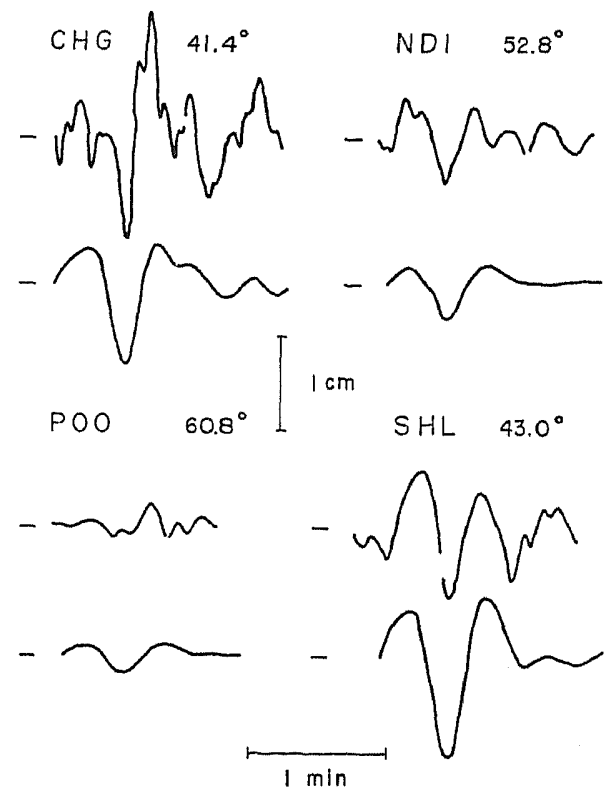

Fig. 18. Recorded and computed $S$ waveforms at four stations in teleseismic distances. Numericals indicate their epicentral distance. 
and hence to the geometry of the fault plane relative to the ground surface, and also strongly subjected to the effects of reflected waves $p P$ and $s P$. For this reason, we do not make further analysis into the far-field $P$ wave observations.

\section{Discussion}

We have discussed possible faulting processes of the southeastern Akita earthquake on the basis of the focal mechanism, spatial distribution of aftershocks, near-field dynamic ground displacements, static displacements, strain changes and far-field seismic observations, taking into consideration the tectonic structure in this region. The results of the present study suggests that there could still be two different interpretations, as indicated by the focal mechanism solution.

The first interpretation is that the present earthquake was caused by an overthrusting fault of a western block against the east side along a westerly dipping fault plane with N-S strike. As have been mentioned earlier, many evidences such as the tectonic and geological features of the N-S trend, the location of the epicenter close to the presumed trace of the Kawafune fault, the tectonic deformations associated with this fault movement and the beltlike distribution of earthquake damages along the trace in the N-S direction, all might be considered to support this interpretation. The last evidence is based on the fact that in case of reverse faulting as in the present earthquake, the upper block used to suffer damages due to larger displacements. The dynamic ground displacements observed in the near-field, the overall pattern of static displacements as well as the features of vertical tectonic movements along the leveling route, and the $S$ wave amplitudes recorded at teleseismic distances, also appear to favor the first interpretation, although these evidences may not be conclusive in view of small differences among the observations and theoretical calculations from various models. This interpretation encounters, however, a severe difficulty to explain spatial distribution of aftershocks apparently inclining towards northeast. If the above interpretation is correct, and if the inclined aftershock distribution is not a result of biased determination, it would follow that many of the aftershocks took place along an auxiliary plane perpendicular to the fault plane. Generation of aftershocks should generally be closely related to re-adjustment of the stress field around the fault plane. Theoretical studies on the stress changes that accompany faulting have been made by Chinnery $(1963,1966)$, Maruyama (1969), Oike (1971) and others. From numerical results, OIKE (1971) suggested a possibility that aftershocks could occur with a mechanism similar to that of the main shock in the direction exactly perpendicular to or along the fault plane but 
with considerably different mechanisms in other directions. In the case of the present earthquake, HASEGAWA et al. (1972) showed that the focal mechanism of aftershocks north of $39^{\circ} 15^{\prime}$ and west of $140^{\circ} 45^{\prime}$ is quite different from that of the main shock but similar to that in other areas. Above evidence suggests a possibility that the former group of aftershocks might not occur along the fault plane. If this is true, the spatial distribution of aftershocks shown in Fig. 3 would not exactly reflect the inclination of the fault plane.

On the contrary, the second interpretation, which is entirely based on the spatial distribution of aftershocks, is that the present earthquake was due to thrust faulting of a northeastern block over a southwest block along a northeasterly dipping fault plane. This interpretation would be difficult to correlate the faulting to the various evidence described above, and to find significant tectonic implications. From closer re-examinations of the epicentral location and topography of the region, HASEGAWA (personal communication, 1973) states that the Mahiru mountain ranges, to which the main part of the Kawafune fault runs parallel just in the east side, do not extend south beyond Kurosawa, and that the present earthquake took place just west of another mountain system including the Yakeishi-dake which runs north-south about $10 \mathrm{~km}$ apart from the former mountains. Also, the southern part of the Kawafune fault cannot be definitely traced but is only an extension presumed from geological and topographical evironments. For these reasons, HASEGAWA (personal communication, 1973) suggests that the faulting mechanism

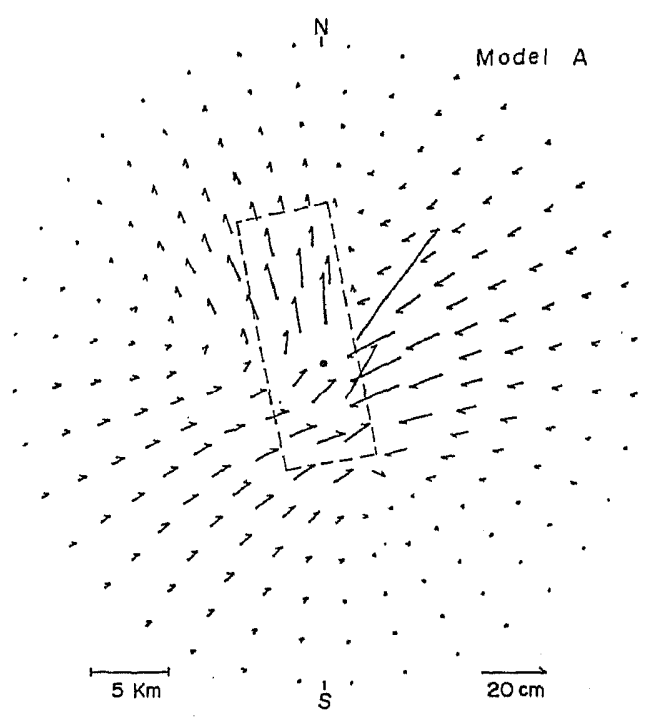

Fig. 19. Pattern of static, horizontal displacements based on Model A. 
of the present earthquake could be entirely independent of the movements of the Kawafune fault, and hence that the second interpretation would not be unreasonable.

It has also been reported (HIRASAWA and IsHII, presonal communication, 1973) that a number of tomb stones in the epicentral area fell down either to the northeast or to southwest direction. This evidence might be accepted to support the second mechanism, but could also be regarded as manifesting the direction of slip motion over the fault plane. Actually, the Model A based on the first interpretation also yields large horizontal ground movements pointing towards the above two directions, as shown in Fig. 19. The above report, therefore, does not seem to give a solution. At this point, however, the second interpretation also cannot be ruled out before further conclusive information is obtained.

Table 1 summarizes the estimated fault parameters for the four probable models based on the two different standpoints. The average fault displacement and the stress drop range from 23 to $65 \mathrm{~cm}$, and from 5 to 19 bars, respectively.

Finally, pre-earthquake data are examined here from the view point of earthquake prediction in relation to the faulting mechanism discussed above. Vertical tectonic movements during the period 1956-1966 over the Tohoku region, which are derived from leveling surveys together with observations of the mean sea level, generally indicate subsidence in the Pacific coastal region and uplift in the Japan Sea coastal region except near Sakata (See Fig. 3, Geographical Survey Inst., 1971). This trend might be due to the compressional tectonic stresses working in the E-W trend over the Tohoku region, which are also confirmed by triangulation survey (Geographical Survey Inst., 1971), resulted from underthrusting of the Pacific Plate.

The present earthquake took place, under the tectonic stresses, in a limited area laid between locally subsided regions of the Kitakami valley and Yokote basin. These situations also appear to favor the first interpretation for the faulting mechanism. Crustal movements during 1956-1966 along the leveling route from Yokote to Kitakami indicate small uplift as shown in Fig. 10. This uplift may be considered as precursory phenomena, since secular level changes of several sites on the route show a common increase during the period, as clearly understood from Fig. 11. The pre-earthquake uplift might be interpreted by the dilatancy model suggested by Scholz et al. (1973). Actually, it has been reported (HASEGAwA et al., 1973b) that there was a decrease of the $V_{\mathrm{p}} / V_{\mathrm{s}}$ velocity ratio during 22 months before the earthquake, as expected from the model. Figure 11 shows, however, that the crustal uplift seems to have initiated at some time between 1956 and 1966, more than 4 years before the earthquake. The discrepancy suggests that the uplift before 
1968 may not be attributed to dilatanc y, but naturally to the general tectonic stress stated above.

It is to be also noted here that the volcano Akita-Komaga-take, $55 \mathrm{~km}$ north of the epicenter of the present earthquake, suddenly erupted on September 17, 1970, and that its daily frequency of eruptions discontinuously decayed to about a half or lower level three days after the earthquake (NAKAMURA, 1971). NAKAMURA (1971) presented an interesting model to explain a possible relation between the volcanic eruption and generation of the earthquake, in which he assumed that compressional crustal strain accumulating around this region prior to the earthquake has caused the volcanic eruption, and that its activity has ceased by strain release due to the generation of faulting. His assumptions seem to be justifield by the pre-earthquake crustal uplift in this region probably due to compressional tectonic stresses, but the areal strain changes of the order of 2.4 and $1.5 \times 10^{-8}$ calculated from Models A and $\mathrm{K}^{\prime}$ seems slightly lower than those expected to release completely the accumulated strains there.

I am grateful to the members of Tohoku University group for providing me various information on the present earthquake in advance of publication of their results: particularly to Dr. Akira Hasegawa and his colleagues for their results of aftershock distribution, Dr. Hiroshi Ishii for their observed results of strain steps, and to Professors Akio Takagi and Ziro Suzuki for general discussion. Dr. Mamoru Katsumata of the Japan Meteorological Agency kindly provided copies of the strong-motion records. I also wish to thank the members of the Research Group of Crustal Movements for providing their observed results of strain steps. Thanks are extended to Mrs. Ritsuko Koizumi for assistance in the present work, Mr. Yoshinobu Hoso for drawing the figures, and to Mrs. Yoko Mikumo for preparing the manuscript.

Computations involved were made at the Data Processing Center, Kyoto University.

\section{REFERENCES}

Chinnery, M. A., The stress changes that accompany strike-slip faulting, Bull. Seism. Soc. Amer., 53, 921-932, 1963.

ChInNery, M. A., Secondary faulting, 1. Theoretical aspects, Can. J. Earth Sciences, 3, 163174, 1966.

Chinnery, M. A. and J. A. Petrak, The dislocation fault model with a variable discontinuity, Tectonophysics, 5, 513-529, 1968.

GEOGRAPHICAL SURVEY INSTITUTE, Vertical, crustal movements before and after the southeastern Akita earthquake, Rep. Coordinating Committee for Earthquake Prediction, 5, 3-8, 1971 (in Japanese).

Geological SURvey Institute, Geological background of the southeastern Akita earthquake, Rep. Coordinating Committee for Earthquake Prediction, 5, 24-27, 1971 (in Japanese).

Hasegawa, T., S. Hori, A. Hasegawa, K. Kasahara, M. Horiuchi and J. Koyama; On the southeastern Akita earthquake of 1970, (1), read at the annual meeting of the Seism. Soc., Japan, April, 1972.

Hasegawa, A., K. Kasahara, M. Horiuchi, J. Koyama, T. Hasegawa and S. Hori, On the southeastern Akita earthquake of 1970, (2), read at the annual meeting of the Seism. Soc., Japan, September, 1972. 
Hasegawa, T., S. Hori and A. Hasegawa, On the southeastern Akita earthquake of 1970, (4), read at the annual meeting of the Seism. Soc., Japan, November, 1973a.

Hasegawa, A., T. Hasegawa and S. Hori, Temporal variation of the $V_{\mathrm{p}} / V_{\mathrm{s}}$ ratio in the case of the southeastern Akita earthquake of 1970, read at the annual meeting of the Seism. Soc., Japan, November, 1973b.

Hashizume, M., K. Oike, S. Asano, H. Hamaguchi, A. Okada, S. Murauchi, E. Shima and M. NogosHr, Crustal structure in the profile across the northeastern part of Honshu, Japan, as derived from explosion seismic observations, Bull. Earthq. Res. Inst., 46, 607630, 1968.

Haskell, N. A., Elastic displacements in the near-field of a propagating fault, Bull. Seism. Soc. Amer., 59, 865-908, 1969.

Ishir, $\mathrm{H} ., \mathrm{T} \cdot \mathrm{SATO}$ and $\mathrm{K}$. TACHIBANA, Observations of crustal movements in the Oga peninsula, Res. Rep. for Natural Disasters in the Tohoku region, 49-61, 1971 (in Japanese).

KawASAKI, Y., Y. Suzukr and R. Sato, Seismic waves due to double couple source in a semi-infinite space, Part 1, Zisin 25, 207-217, 1972; Part 2, Zisin 25, 333-342, 1972 (in Japanese).

MARUYAMA, T., On the force equivalents of dynamical elastic dislocations with reference to the earthquake mechanism, Bull. Earthq. Res. Inst., 41, 467-486, 1963.

Maruyama, T., Statical elastic dislocations in an infinite and semi-infinite medium, Bull. Earthq. Res. Inst., 42, 289-368, 1964.

Maruyama, T., Stress fields in the neighborhood of a crack, Bull. Earthq. Res. Inst., 47, 1-29, 1969.

Matuzawa, T., On the crustal structure in North-east Japan by explosion seismic observations, Bull. Earthq. Res. Inst., 37, 123-154, 1959.

Microearthquake Research Group of Tohoku University, On an earthquake that occurred in the southeastern part of Akita Prefecture, Rep. Coordinating Committee for Earthquake Prediction, 5, 14-21, 1971 (in Japanese).

Mrkumo, T., Source process of deep and intermediate earthquakes as inferred from long-period P and S waveforms, 1 and 2, J. Phys. Earth, 19, 1-19, 1971; 303-320, 1971.

Mrкumo, T., Faulting process of the San Fernando earthquake of February 9, 1971 inferred from static and dynamic near-field displacements, Bull. Seism. Soc. Amer., 63, 249-269, 1973a.

Mikumo, T., Faulting mechanism of the Gifu earthquake of September 9, 1969 and some related problems, J. Phys. Earth, 21, 191-212, 1973 b.

Nakamura, K., Volcano as a possible indicator of crustal strain, Bull. Vol. Soc. Japan, 16, 63-71, 1971. (in Japanese)

Orke, K., Distribution of Stresses and dynamic displacements around a fault, $Z$ isin, 24, 318334, 1971 (in Japanese).

SATo, R., Seismic waves in the near field, J. Phys. Earth, 20, 357-376, 1972.

Scholz, C. H., L. R. Sykes and Y. P. Aggarwal, Earthquake prediction: A physical basis, Science, 181, 803-810, 1973.

Strong Motion Earthquake Observation Committee, Strong-motion earthquake records in Japan, Vol. 12, 1971.

TAKagi, A., A. Hasegawa, T. Hasegawa and S. Hori, On the southeastern Akita earthquake of 1970, (3) read at the annual meeting of the Seism. Soc., Japan, May, 1973. 